\title{
PERSEO EN LA COMEDIA TARDOBARROCA: IGNACIO FERRERA Y PASQUAL ${ }^{1}$
}

\author{
ESTHER FERNÁNDEZ LÓPEZ \\ Universidad Nacional de Educación a Distancia \\ fernandezlopezesther@gmail.es
}

L

a fábula de Perseo constituye uno de los mitos grecolatinos que gozaron de mayor popularidad en su transmisión desde la Antigüedad clásica hasta la Edad Media. De ahí que conociera múltiples adaptaciones en la mayor parte de las naciones europeas, en su mayoría basadas en las Metamorfosis de Ovidio ${ }^{2}$. Versiones a las lenguas vulgares, moralizaciones alegóricas y tratados mitográficos abordaron la historia de Perseo con mayor o menor fortu$\mathrm{na}^{3}$. Y, por supuesto, también en la literatura encontramos diversidad de obras y

1 El contenido del presente artículo forma parte de la tesis doctoral de la autora, cuyo depósito en la Universidad Nacional de Educación a Distancia se encuentra en vías de tramitación.

2 La narración de los hechos relativos a Perseo en las Metamorfosis ovidianas se extiende entre el Libro IV, v. 607 y el Libro V, v. 249.

3 En castellano encontramos, sucesivamente, cuatro traducciones del poema ovidiano en el siglo xvi: la de Jorge de Bustamante, en prosa, que data de la primera mitad de esa centuria (editada sin fecha «en Anvers») y fue la que alcanzó mayor éxito y difusión; y otras tres en verso, todas ellas tributarias en mayor o menor medida de las italianas de Dolce y Anguilara: la de Antonio Pérez Sigler (Burgos, 1580); la de Felipe Mey, que se limita a los siete primeros libros (Tarragona, 1586); y la de Pedro Sánchez de Viana (Valladolid, 1589). Con anterioridad a todas ellas se compusieron dos obras magnas basadas en diversas fuentes europeas que incorporaban la mitología clásica dentro de una pretendida Historia Universal: la General Estoria, surgida en el siglo xiii de los talleres alfonsíes; y en el xv, el tratado Sobre Eusebio de Alonso Fernández de Madrigal (llamado El Tostado): extensa amplificatio del Libro de los tiempos compuesto en griego por Eusebio de Cesarea en el siglo iv y traducido al latín por San Jerónimo en la centuria siguiente. Tanto la obra ordenada por el Rey Sabio como la de Madrigal suponen una combinación de elementos historiográficos con otros de carácter mitográfico en los que se da pie a todo tipo de interpretaciones (básicamente, tres: la evemerista, la astralista y la alegórica). También del siglo XV datan los Morales de Ovidio, versión castellana del Ovidius moralizatus del benedictino francés Pierre Bersuire. La traducción se debe a Alfonso de Zamora y, al igual que la compilación del Tostado, se llevó a cabo por encargo del Marqués de Santillana. Por último, como tratados propiamente mitográficos destacamos otras dos obras publicadas en los Siglos

Edad de Oro, XXXIV (2015), pp. 169-186, ISSN: 0212-0429 - DOI http://dx.doi.org/10.15366/edadoro2015.34.011 
autores que recrearon las aventuras del héroe argivo: hijo de Júpiter (fruto de su unión con Dánae en forma de lluvia de oro), el pequeño y su madre son abandonados en un arca flotante por Acrisio, rey de Argos y padre de Dánae (quien de esta forma pensaba eludir un oráculo según el cual el hijo de Dánae acabaría dándole muerte). Es así como madre e hijo arriban a las costas de Sérifos, donde el niño será recogido por un pescador llamado Dictis y criado por Polidectes (Piluno en otras versiones), soberano del lugar ${ }^{4}$. Llegado a su juventud, Perseo es enviado por el rey a dar muerte a la horrible gorgona Medusa, que transformaba en piedra a todo aquel que la mirase. Tras decapitar al monstruo (con la ayuda de unos objetos mágicos que le proporcionan Mercurio, Minerva y Plutón), Perseo empleará su mortífera cabeza para petrificar a sus enemigos. Así, el joven vence con el letal despojo al gigantesco rey Atlas (que le había negado hospitalidad temiendo que el héroe le robase las manzanas doradas del jardín de las Hespérides); libera a la bella princesa etíope Andrómeda del monstruo marino al que había sido expuesta como tributo para aplacar la cólera de los dioses; y, desposado con la doncella, deberá hacer frente al ejército dispuesto por Fineo (tío y antiguo prometido de Andrómeda), al que acaba venciendo mediante, de nuevo, la exhibición de la monstruosa cabeza. De regreso a Sérifos, el héroe volverá a emplear su arma mortal contra Polidectes, quien había aprovechado su ausencia para tratar de forzar a Dánae. Finalmente, Perseo y Andrómeda, junto con Dánae, se trasladan a Argos, donde el joven emplea una vez más la cabeza de la gorgona para vencer a Preto (hermano de Acrisio, que había reunido un ejército para rebelarse contra este y arrebatarle el trono). Sin embargo, el final no será del todo feliz; pues el oráculo acabará por cumplirse debido a un fatal accidente, al alcanzar mortalmente a Acrisio un disco lanzado por su nieto durante unos juegos.

Como también ocurre con el resto de leyendas mitológicas, en la literatura española la historia de Perseo se abordaría principalmente a través de dos géneros: poesía y teatro. Los primeros textos literarios que adaptaron nuestro mito fueron los del romancero ${ }^{5}$, para evolucionar más tarde hacia el

de Oro: la Filosofía secreta de Juan Pérez de Moya (Madrid, 1585) y el Teatro de los dioses de la gentilidad, de Fray Baltasar de Vitoria (en dos partes, publicadas ambas en Salamanca; respectivamente, en 1620 y 1623 ).

4 Cabe advertir que toda la parte inicial de nuestro mito se encuentra ausente en el poema ovidiano original (salvo una fugaz alusión al episodio de la lluvia de oro en IV, v. 611), pues este comienza el relato in medias res, en pleno vuelo de Perseo (merced a las sandalias aladas de Mercurio) sobrevolando los dominios de Atlas tras la decapitación de Medusa. No obstante, los detalles sobre los orígenes de Perseo sí aparecen en la versión castellana de Bustamante, que fue manejada con profusión por los autores que abordaron la historia y que incorporaba elementos procedentes de otras fuentes antiguas (en este caso, básicamente, la Biblioteca de Apolodoro).

5 Así, ya en el Romancero Viejo encontramos tres poemas sobre el mito que serían recogidos por el valenciano Juan de Timoneda en sus Rosas de romances (1573). Quince años después, Juan de 
soneto $^{6} \mathrm{y}$, con mayor extensión, la fábula mitológica en arte mayor ${ }^{7}$. En cuanto al género dramático, nuestros dos máximos autores barrocos, Lope de Vega y Calderón de la Barca, dedicaron a Perseo sendas comedias mitológicas: respectivamente, La fábula de Perseo o La bella Andrómeda, compuesta hacia 1612, y Las fortunas de Andrómeda y Perseo (1653). Calderón volvería sobre el mito en uno de sus últimos autos sacramentales: Andrómeda y Perseo (1680), obra maestra del género en la que la fábula pagana se convierte en un trasunto de la historia de la Redención.

Estas obras de nuestros dos dramaturgos áureos más geniales supondrán la culminación del mito de Perseo en las letras españolas. Sin embargo, el siglo XVIII nos ofrecerá todavía algunas muestras tardías del teatro barroco. En efecto, se tiene noticia de un drama (hoy perdido) titulado Andrómeda y Perseo, compuesto por Jacint Balaguer Perelló hacia 1741 y que habría sido representado en la Casa de les Comèdies de Palma entre 1742 y 1748. Por el contrario, sí ha llegado hasta nosotros una versión anónima del auto calderoniano que ha sido editada por Ruano de la Haza junto con el texto original de Calderón. Pero, además de estas obras, encontramos todavía en esta centuria una curiosa comedia sobre el mito que supone una de las últimas muestras del Arte Nuevo (ya para entonces en su fase final) que lo abordaron en nuestras letras. Se trata de la pieza publicada bajo el triple título de Comedia nueva- También habla lo insensible, Los encantos de Medusa $y$ Aventuras de Perseo 8 .

Y es que, muy a pesar de los reformistas ilustrados, el espectador dieciochesco seguía disfrutando con el gran teatro clásico español. En efecto, las obras de nuestros dramaturgos del Siglo de Oro continuaron representándose con gran éxito a lo largo de toda la centuria; y tampoco faltaron los cultivadores de la corriente barroquizante en obras de nueva creación, que gracias al perfeccionamiento de las técnicas escenográficas no hicieron sino aumentar su espectacularidad. Como señala Emilio Palacios Fernández, estos autores «vierten en odres nuevos

la Cueva compone otro (de considerable extensión) que incluirá en su Coro febeo de romances historiales (1588).

6 Entre los autores que nos dejaron sonetos sobre nuestro mito encontramos a Juan de Arguijo, Lope de Vega o Miguel Colodrero de Villalobos.

7 Entre ellas sobresale La Andrómeda de Lope, incluida en su volumen La Filomena (1621).

8 Además de las versiones puramente teatrales del mito de Perseo, nos ha llegado una muestra de comedia musical en una insólita zarzuela debida al sacerdote Tomás Añorbe y Corregel (Zarzuela nueva. Júpiter y Dánae, Madrid, 1738), obra en la que se nos presenta una extraña historia de amor entre Dánae y Piluno anterior a la lluvia de oro. Se conserva asimismo la partitura de otra zarzuela musical (Júpiter y Dánae. Zarzuela en tres jornadas, y baile), debida al mallorquín Antonio Literes (1673-1747). Si bien no nos ha llegado el nombre del libretista, pensamos que podría tratarse de José de Cañizares (1676-1750). 
las viejas fórmulas para adaptarlas a los gustos del público y a los progresos del arte escénico»?.

Pese a todo, la pieza que nos ocupa no se adapta a ninguno de los géneros que este mismo crítico señala para el teatro tardobarroco ${ }^{10}$. Editada en Barcelona en diciembre de 1743 («por Joseph Giralt, impresor»), nuestra obra está firmada por un autor llamado Ignacio Ferrera y Pasqual, que en el verso final se nos presenta como «un catalán ingenio» ${ }^{11}$.

Además del Imprimatur, diversos rasgos lingüísticos diseminados a lo largo del texto — bien que de forma aislada - parecen atestiguar tal origen geográfico: entre ellos, voces como farigola ('tomillo'); el cierre en $u$ de la $o$ átona (sumanta por somanta, lo que también podría interpretarse como un vulgarismo puesto en boca del gracioso Culebrina); cambios en el género morfológico (algún señal); empleo del que expletivo - con valor de 'acaso' - en la interrogación (¿que es dueño de mi albedrío?); e incluso algún breve pasaje compuesto íntegramente en catalán popular, puesto asimismo en boca del gracioso con clara intencionalidad cómica. Pese a todo ello, junto a los catalanismos aparecen igualmente en el texto otros muchos rasgos lingüísticos que demuestran el conocimiento del castellano coloquial y - lo que resulta más desconcertante- diversos casos de laísmo (típico del habla de Madrid y Toledo); pero también la alusión a «la oliva» para referirse a un olivo (fenómeno frecuente en Andalucía). Todo ello contribuye en no poca medida a rodear de un cierto halo de misterio el origen lingüístico y, por tanto, geográfico de este desconocido autor.

La obra comprende un total de 3.123 versos - con diversidad de métrica y combinaciones estróficas- y presenta la típica hechura de una comedia áurea: estructura dividida en tres jornadas, nómina de personajes-tipo propios de nuestro teatro clásico (galán, dama, gracioso, viejo), presencia de una trama secundaria y

9 Véase Emilio Palacios Fernández (2003: 1554), quien explica cómo, entre los dramaturgos tardobarrocos, se observa una tendencia a la hibridación, «a cambiar argumentos y situaciones, en especial aquellas que habían resultado del agrado del público» (2003: 1557).

10 La clasificación de Palacios abarca tres modalidades: el teatro espectacular (subdividido a su vez en comedias heroica y militar, comedia de santos y comedia de magia); teatro romancesco (de acción y aventuras, centrado en las historias de guapos y bandoleros en la primera mitad de la centuria y en el drama sentimental en la segunda mitad); y teatro costumbrista, donde se incluye la llamada comedia de figurón (2003: 1556-1557). Así pues, no parece que los asuntos mitológicos resulten muy representativos de este tipo de obras, lo que situaría esta comedia, en cuanto al género, en un término medio, a caballo entre la comedia barroca y la propiamente tardobarroca.

11 Francisco Aguilar Piñal cita esta obra y a su autor en la Bibliografía de autores españoles del siglo xviii, vol. III, Madrid: CSIC, 1981-1995, 3769; véase Francisco Mendoza Díaz-Maroto (1999: 119). Por nuestra parte, pensamos que podría tratarse del mismo dramaturgo que también compuso una Comedia famosa intitulada: Conquistar un imposible. De un ingenio catalán, sin nombre de autor ni lugar ni fecha de edición; aunque en la portadilla sí que consta la indicación: «Véndese en casa de Ignacio Guasch Impresor, en la calle de la Bocaria». 
de carácter cómico protagonizada por los criados. A ello se añade la manipulación de la materia mitológica que ya se observaba en las piezas de Lope y Calderón basadas en la historia de Perseo, con adiciones y supresiones de determinados personajes, cambios en el desarrollo de la acción y, sobre todo, una difícil confluencia de los elementos paganos con los de tradición judeo-cristiana.

Entre los aspectos que más nos llaman la atención figuran los espacios dramáticos. Así, Perseo es originario de Argos, cuyo rey, su abuelo Acrisio, se había negado a otorgarle en herencia la corona por tratarse de un bastardo (por más que el padre de Perseo no fuese sino el propio Júpiter). Un segundo espacio sería Apulia, donde el joven - por alguna razón que no se especifica, ya que el autor omite el episodio del arca abandonada - habría pasado parte de su vida y tenido amores con una dama llamada Diana, hermana del rey Pilumno ${ }^{12}$. Por su parte, la acción de la obra se sitúa en su totalidad en Etiopía, reino de Cefeo (el padre de Andrómeda) en el que también habita Medusa. Según se nos explica, Palas se apareció a Perseo para anunciarle que allí sería feliz con Andrómeda si libraba a su tierra de la monstruosa gorgona -enemiga de la diosa- y de sus dos hermanas (que, al parecer, son igualmente mortales, cuando en el mito original no lo son).

Esta es, pues, la razón de la travesía que conduce hasta la tierra de Cefeo a Perseo y su séquito. Entre los acompañantes del héroe destacan su criado Culebrina y su amigo Telamón, cuya misión —encomendada también por Palas- consiste en encontrar la guarida de Medusa para conducir al héroe hasta ella. El rey promete a Perseo la mano de su hija a cambio de la hazaña de matar a la gorgona. Durante la ceremonia de los esponsales, es el propio Cefeo - y no su esposa Casiopea, que no aparece en la obra- quien alaba la belleza de Andrómeda y la juzga superior a la de las nereidas ${ }^{13}$. Como reacción a la blasfemia, extrañamente es Medusa la que se siente agraviada por semejante ofensa a estas criaturas marinas y la que propicia la sentencia del dios del mar. A través del anciano sacerdote Dante, Neptuno decreta el sacrificio de Andrómeda, condenada a ser devorada por el monstruo marino. Poco después, Medusa da a luz a Pegaso, que - muy a pesar de la gorgona- servirá de cabalgadura al héroe para el rescate de la Infanta ${ }^{14}$, pese a que esta intenta disuadir a su amado. Tras la liberación de la doncella, el pueblo de Etiopía aclama a los esposos.

12 El personaje de Diana, que solo aparece como una mención, corresponde a una invención de Ferrera y Pasqual.

13 En el mito original, la ofensa de Casiopea y el dictamen de Júpiter sobre el sacrificio de Andrómeda se producen con anterioridad a la llegada de Perseo.

14 En Ovidio, Pegaso nace efectivamente de Medusa para salir volando y dar lugar a la fuente de los poetas; sin embargo, este nacimiento se produce a continuación de la decapitación de la gorgona. En cuanto al vuelo de Perseo, originariamente se debe a las sandalias de Mercurio, aunque con posterioridad se identificó al caballo alado con la montura del héroe, y así aparecería en ilustraciones a la narración e incluso en representaciones pictóricas. 
La particularidad del texto de Ferrera reside en el hecho de que todos los acontecimientos hasta ahora referidos suceden en la Jornada Primera y sin que el héroe haya dado muerte a Medusa, mientras que en las otras dos - es decir, en la parte más extensa de la obra - el autor desata su imaginación para construir una trama ciertamente alejada del relato mítico original, en la que tienen cabida una serie de elementos más propios de una comedia de enredo que de una obra de asunto mitológico. Entre ellos destacan diversos «encantos» — los que se anunciaban desde el propio título- llevados a cabo por las artes de hechicería de Medusa con la ayuda de sus dos hermanas, Euriala y Sthenio, las cuales cobran en nuestra comedia un inusitado protagonismo. Así, Medusa recurre a la transformación del aspecto de diversos personajes para urdir sus engaños, como cuando disfraza al gracioso Culebrina bajo la apariencia de un dragón o, más tarde, de la propia Medusa. En otro momento, la gorgona hace que su hermana Sthenio adopte la figura de Diana para hacer creer a Perseo que se encuentra en Apulia y así dar celos a Andrómeda. También para provocar celos, en este caso los de Perseo, Medusa hechiza a sus hermanas para que tomen el aspecto de Andrómeda y Telamón y así fingir un romance entre ellos.

En todas estas transformaciones y disfraces observamos un claro influjo de la comedia de magia dieciochesca, si atendemos a la crítica de este tipo de obras publicada en 1794 en el ilustrado Memorial literario. El autor del artículo (que apareció con motivo del reestreno de El asombro de Jerez, Juana la Rabicortona, de Cañizares) arremete, entre otros aspectos, contra la presencia del típico personaje de

un vejete que danza en todo, porque debe de ser precepto del arte cómico-mágico que no hay composición de estas en que no dance semejante personaje, para que los señores nigromantes diviertan al auditorio, transformándole en algún avechucho o cosa ridícula. (Palacios: 1654)

En este caso, el «vejete» se habría sustituido por Culebrina; aunque también otros personajes sufren las artes mágicas de esta particular Medusa creada por Ferrera y Pasqual (el hecho tampoco sorprende demasiado, teniendo en cuenta que el propio título de la obra se refiere a «los encantos de Medusa») ${ }^{15}$.

Precisamente, el fingido romance protagonizado por los falsos Andrómeda y Telamón se convertirá en el elemento que acabe precipitando el desenlace: en efecto, Telamón — acusado y retado por Perseo debido a la presunta infidelidaddecide hacer méritos encontrando al fin el escondite de Medusa. Desgraciadamente, el logro de su objetivo conllevará su propia muerte, ya que la gorgona lo petrifica con la mirada. A continuación, muy ufana, dedica un extenso discurso a

15 Julio Caro Baroja clasifica las comedias de magia en tres subgéneros fundamentales: de magos, de magas y de encantos. La de Ferrera pertenecería a esta última modalidad, correspondiente a unas obras que «se llenan de lances y episodios mágicos» (Palacios: 1563). 
refocilarse cruelmente en el triste destino del joven, insistiendo en particular en la imposibilidad de que «lo insensible» pueda ahora hablar para mostrar a Perseo el escondite de su enemiga - se trata de una nueva alusión al título de la obraSin embargo, el triunfo de Medusa será solo aparente, pues de hecho supondrá el cumplimiento de la hazaña del héroe, ya que Perseo descubre el lugar donde se encuentra la gorgona después de encontrarla precisamente durmiendo a los pies de la estatua en que ella misma ha convertido al infortunado Telamón (en cuya lealtad ha vuelto a confiar Perseo tras aclarar las cosas con su amada). De esta manera, como observan con insistencia varios personajes, queda demostrado cómo a veces «también habla lo insensible».

Finalmente, se celebran las bodas entre Andrómeda y Perseo, cuyo matrimonio no había podido aún consumarse debido a que el héroe se había visto obligado por Palas a prometer que no lo haría hasta haber dado muerte a Medusa. La obra acaba con un emotivo recuerdo de Telamón, cuya estatua se coloca en el salón del palacio como homenaje permanente a su heroica contribución a la hazaña de Perseo, y con la apoteósica exaltación final del héroe, en una escena en la que baja un coro de dioses dispuestos a asistir a la celebración de las bodas y la mismísima Palas agradece a Perseo su acción y le otorga la mano de Andrómeda (la escena recuerda al final de las calderonianas Fortunas de Andrómeda y Perseo).

Entre los elementos propios de nuestro teatro clásico destaca, como ya indicábamos más arriba, la presencia de una trama secundaria protagonizada por los criados y que, en este caso, desarrolla el grotesco romance entre Culebrina y la doncella de Andrómeda, llamada Larina, romance que culmina con el anuncio del enlace nupcial entre ambos. No obstante, hay que señalar que en este caso el protagonismo del gracioso resulta un tanto sobredimensionado en detrimento de la presencia del héroe, cuya historia más bien parece una mera excusa para poner en escena una comedia al más puro estilo del teatro barroco español.

En este sentido, la obra de Ferrera manifiesta una evidente admiración de nuestro autor por el Arte Nuevo y por los grandes maestros áureos en una época en la que ya no faltaba mucho para que estallase la crítica feroz de los ilustrados al teatro nacional barroco. Buena muestra de ello es la imitación -o más bien podríamos hablar de calco- del primer monólogo de Segismundo en la comedia calderoniana La vida es sueño (vv. 78-172) que encontramos en la Jornada Primera de nuestra obra (vv. 753-823). El pasaje, puesto en boca de Andrómeda, corresponde al momento de su exposición al monstruo marino y reza como sigue:

[...] que porque hermosa fui, soy infelice.

Apurar, hados, pretendo

vuestro severo rigor,

pues el golpe del dolor 
ya me acaba en el estruendo.

Vuestros influjos, entiendo

de menos justos culpar,

pues si me quisisteis dar

hermosura, ¿para qué

la disteis, si solo fue,

para haberla de quitar?

Solo quisiera entender,

para apurar más mi queja,

esa violencia refleja,

que tenéis en ofender.

Si a dos los dejáis nacer

con una fortuna igual,

¿por qué después desigual

los sigue contraria suerte,

que lo que al uno da muerte

da al otro dicha cabal?

Nace el pintado jilguero

de hermosura matizado,

ya del bosque, ya del prado,

ramillete lisonjero;

y si tal vez prisionero

la libertad pierde amada,

halla vida regalada

en la prisión bulliciosa;

¡y porque yo nací hermosa

he de morir desdichada! (I, vv. 753-783)

El lamento de Andrómeda transcurre en parecidos términos a lo largo de otras tres estrofas en las que la muchacha se compara sucesivamente con «el hermoso Clavel», con el Día y con «la diáfana Fuente», hasta que el soliloquio se cierra — fiel al modelo calderoniano- con los versos siguientes:

En llegando a esta pasión,

el corazón me arrancara,

si advertida no mirara

que arcanos divinos son.

Bien sabe vuestra razón

sabia, infalible, eminente,

por qué me niega prudente

aquel placer lisonjero,

que corresponde al jilguero,

al día, clavel y fuente. (I, vv. 814-823) 
También podemos rastrear otros guiños del autor a las producciones más célebres de nuestra comedia clásica en el disparatado soneto dedicado a Larina (II, vv. 425-449) que Culebrina compone «de repente» en la Jornada Segunda - la expresión remite al célebre poema lopesco-; o en las diversas alusiones metateatrales que este mismo personaje va haciendo a lo largo de la obra. Entre todas ellas destacamos la siguiente, en la que el gracioso se presenta como un actor que solo está interpretando a un personaje en una comedia:

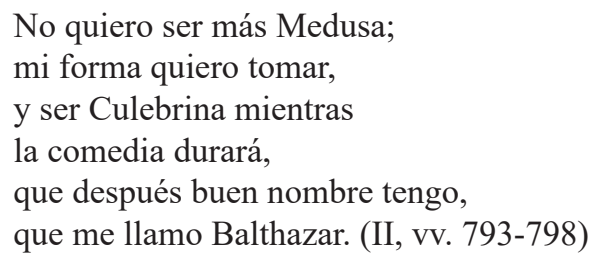

Por lo que se refiere a la métrica, en la obra predomina el romance, en general distribuido en cuartetas; pero también encontramos multitud de estrofas de arte mayor y/o menor, como la octava real, las series de coplas, o de octosílabos blancos, el soneto, la silva, las combinaciones de pareados o incluso el ovillejo. El autor demuestra así una considerable destreza compositiva, si bien no faltan algunas irregularidades - bien que muy ocasionales-a lo largo del texto ${ }^{16}$.

En cuanto a la fidelidad a la materia mitológica clásica, hay un aspecto que llama sobremanera nuestra atención, y es el hecho de que tanto Andrómeda como el resto de los personajes etíopes tienen la piel negra, como se declara explícitamente en diversos pasajes de la comedia. En efecto, al principio de la obra, Perseo, recién desembarcado, refiere cómo un buen día, estando aún en Argos, fue favorecido con la aparición de Palas instándole a trasladarse a Etiopía. En esa tierra le aguarda una misión: la de acabar con Medusa; y también en ese reino le aguarda a Perseo el amor, como relata el propio héroe ${ }^{17}$ :
Dichosa hará, y feliz, dijo, tu mano una regia hermosura, una belleza, que aunque negro el color, es soberano portento de la gran naturaleza; pues la hizo tan perfeta, que no en vano

\footnotetext{
16 Como indica Emilio Palacios (2003: 1555), la comedia tardobarroca continúa empleando la polimetría, aunque con tendencia hacia el romance. Así pues, podríamos observar en este aspecto de la pieza de Ferrera un rasgo que la acerca propiamente a esta corriente; aunque lo cierto es que nuestro «catalán ingenio» se maneja con soltura, y aun con maestría, en el arte de componer versos de todo tipo.

17 Tanto en este como en los otros pasajes citados la cursiva es nuestra.
} 


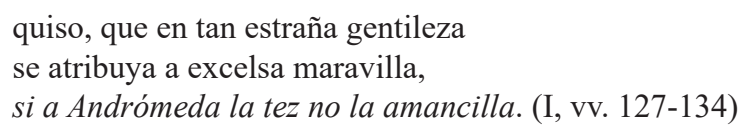

Poco después aparece Medusa, que espía al héroe por estar al corriente de las intenciones de este gracias a sus artes mágicas (I, vv. 207-236). Y a continuación encontramos la siguiente acotación: «Escóndese Medusa en una nube entre los bastidores, salen el Rey, Andrómeda y Larina, todos negros». Más adelante reaparece Medusa, ahora junto a las otras dos gorgonas y se queja ante sus hermanas de lo que juzga la desdicha de todas ellas, tachadas de monstruos por los habitantes de Etiopía:

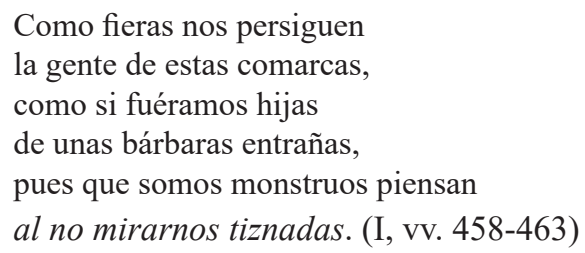

Ya en la Jornada Segunda asistimos a un coloquio amoroso entre Perseo y Andrómeda en el que de nuevo se abunda en el color de la piel de la princesa. El héroe galantea a la doncella en un discurso lleno de requiebros, comparándola primero con la "estrella" de Venus y a continuación con el mismo sol; y asegura que la aurora se retiraría al ver la resplandeciente belleza de Andrómeda. A lo que la muchacha responde con donaire, riéndose de sí misma a cuenta de su tonalidad cutánea:

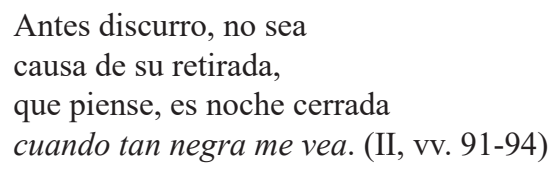

Una última muestra de esta peculiaridad la hallamos en otro diálogo, esta vez de carácter sarcástico, entre el gracioso Culebrina y la criada Larina:

CULEBRINA: [...] ¿Y usted tuvo mucho miedo?

LARINA: $\quad$ El bastante.

CULEBRINA: Pues entienda que a mí también miedo me hace el mirar mujer tan fea.

LARINA: ¿No ves, que de este color son todas las de esta tierra?

CULEBRINA: Yo creo que no será, 


\section{sino olla de Chiminea.}

Mas dime, cuál es tu gracia, que ya es tiempo de saberla, pues que tu nombre no oímos

LARINA: $\quad$ Larina me llamo. CULEBRINA:

Nunca

visto había harina negra. (II, vv. 261-274)

Los citados ejemplos nos parecen dignos de estudio en tanto que son muy pocos los testimonios antiguos que nos presentan una Andrómeda negra ${ }^{18}$. Por alguna razón, Ferrera parece tener algún interés en dejar claro que no solo su Andrómeda sino también el resto de personajes etíopes de la obra se caracterizan por este rasgo étnico. Un aspecto, este último, en el que no parece que se recrearan las escasas fuentes clásicas que se plantearon la cuestión, y que la limitaron exclusivamente a la princesa, pero no así a sus padres ni a sus invitados ${ }^{19}$. Quizá el autor intentara con ello introducir en su obra un elemento exótico, además de la utilización pretendidamente cómica del aspecto racial ${ }^{20}$.

18 En efecto, la práctica totalidad de las fuentes antiguas nos describen a la princesa como una bella joven de piel blanca, tan blanca que desde lejos, según Ovidio en sus Metamorfosis (IV, 673-675), Perseo la había confundido inicialmente con la estatua marmórea de una diosa. Sin embargo, el propio Ovidio nos muestra en algunos pasajes de su producción una Andrómeda de piel oscura, rasgo más acorde con su adscripción etíope. Cristóbal López (1997) rastrea en un interesante artículo los pasajes en los que el sulmonense atestigua esta peculiaridad. El primero pertenece a las Heroidas, y en concreto a la epístola de Safo a Faón (XV, 35-36), donde la poetisa se excusa de no ser blanca argumentando que tampoco lo era Andrómeda, lo que no impidió a la princesa etíope enamorar a Perseo. Los otros fragmentos pertenecen al Ars amatoria, y son tres: I, 51-54, donde Ovidio señala al lector que para encontrar mujeres de piel exótica no hace falta irse lejos como Perseo, pues también las hay en Roma; II, 641-642, donde se toma la supuesta negrura de Andrómeda como ejemplo de que el amante debe ser capaz de disculpar los «defectos» de la amada; y III, 189-192, donde aconseja a las mujeres morenas vestir de colores claros (como asegura hacía Andrómeda) pues el contraste les favorece estéticamente. En la literatura española esta característica solo aparece explícitamente, que sepamos, en dos obras literarias: una, ya citada por Cristóbal López, es un soneto del pintor y poeta Francisco Pacheco, suegro de Velázquez; la otra, la comedia de Ferrera y Pasqual que nos ocupa, y que no se menciona en el citado artículo. Por otro lado, encontramos también un testimonio de que los etíopes son negros en una anónima Fábula de Andrómeda y Perseo que Cossío fecha hacia 1640 y que, según hemos podido determinar por nuestra parte, dataría como máximo de mediados de esa centuria.

19 En efecto, si la presentación de una Andrómeda negra obedece a un afán de rigor y verosimilitud en el soneto de Francisco Pacheco mencionado en nuestra nota 18, en el caso de Ferrara la coherencia es aún mayor, al extenderse este rasgo étnico a todos los etíopes (y, por supuesto, a Cefeo, del que nada se dice al respecto en las fuentes antiguas).

20 Cierto es que la negrura de la piel solo se presenta como rasgo de fealdad aplicado a Larina, pero también que en la obra se considera que Andrómeda es hermosa a pesar de sus rasgos étnicos, lo que muestra los prejuicios raciales de la época. 
Aún más chocante resulta el comentario de Medusa, referido al hecho de que ella y sus hermanas son diferentes a los etíopes, al no estar «tiznadas» como ellos ${ }^{21}$. Un comentario que nos lleva a plantearnos dos reflexiones: la primera, el misterio sobre la patria de las gorgonas, pues la obra nada dice al respecto. Y, en segundo lugar, a concluir que estas criaturas sienten en sus carnes el rechazo de los etíopes, que las consideran monstruosas, en este caso por no ser negro el color de su piel. Sin embargo, el argumento no parece sostenerse, pues los naturales de Etiopía acogen con gran hospitalidad a Perseo y su séquito, que no comparten la tonalidad oscura de su piel; $y$, por otro lado, Medusa no parece asociar el rechazo de los etíopes a las culebras que adornan sus cabellos, ni tampoco la peculiaridad de que su mirada resulta petrificadora. A todo lo cual, además, se añade en la obra el hecho de que Medusa es una poderosa hechicera.

Por lo que se refiere al tratamiento de la materia mítica por Ferrera, cabe mencionar también otros aspectos, algunos ya comentados más arriba:

1) En primer lugar, destaca la ausencia de diversos personajes de la historia original como Casiopea y Dictis, mientras que el rey de Sérifos se llama Pilumno. Como contrapartida, aparecen otros personajes nuevos, como el del sacerdote Dante o el de Diana. También podemos referirnos aquí a la aparición de Palas. Todo ello, al margen de la nutrida retahíla de personajes propios de la comedia barroca (criados, séquitos...).

2) Asimismo desaparecen diversos pasajes del mito, como el abandono en el arca de Dánae y el pequeño Perseo o los relacionados con Atlas y con Fineo.

3) Como contrapartida, en los personajes propios del mito que sí se conservan en nuestra comedia se producen diversos cambios respecto al relato grecolatino. Entre ellos, el papel asumido por las hermanas de Medusa o la asunción por esta del saber astrológico que en las fuentes correspondía al gigante Atlas, y que aquí se combinan con supuestas artes de hechicería.

4) También resultan destacables las circunstancias del nacimiento de Pegaso, que no surge de la sangre de Medusa tras la decapitación de esta, sino que nace en un parto normal, asistida la gorgona por sus hermanas. A continuación, la criatura sale volando y, después de hacer brotar la fuente Hipocrene, servirá a Perseo como cabalgadura para dar muerte al monstruo marino. Además, poco después Culebrina dará cuenta del catasterismo que ha experimentado Pegaso.

${ }^{21}$ Esta alusión al hecho de que los etíopes están «tiznados» remite a la historia de Faetón, hijo del Sol. Según este mito, el inexperto joven fue el responsable de un catastrófico accidente con el carro de su padre, ya que, al no saber manejarlo con destreza, perdió el control y casi incendia la Tierra. La caída del carro incandescente se habría producido en Etiopía, lo que habría provocado que los habitantes de esa tierra se chamuscaran, de donde procedería el color negro de su piel (Grimal 1986: 191, s. v. Faetonte). 
5) En lugar de la ausente Casiopea, es Cefeo el que alaba impíamente la belleza de su hija como superior a la de las nereidas. La divinidad agraviada no es, pues, directamente una diosa como Juno o Venus (las fuentes varían también a este respecto), sino, de forma indirecta, Neptuno, como padre de las ninfas marinas. Pese a ello, será Medusa la que urde el engendramiento por el dios de la fiera marina para castigar la afrenta.

6) Por otro lado, la relación de Medusa con Neptuno resulta sorprendente, pues por una parte se nos cuenta que este dios la violó en el templo de Palas - de donde surgen los deseos de venganza de la diosa virgen por la profanación y su enemistad con la gorgona - dando lugar a su preñez; pero, por otra parte, observamos una gran devoción de Medusa hacia este dios, al que se refiere como «su abuelo» (quien, por otro lado, arrastra con Palas una antigua enemistad relacionada con la disputa de ambas deidades por la consagración de la ciudad de Atenas).

7) Como ya hemos comentado, se da en nuestra comedia una evidente alteración cronológica de los elementos de la fábula, ya que la muerte de Medusa no se produce hasta el final, mientras que la liberación de Andrómeda aparece en la Primera Jornada y es consecuencia de un plan urdido por la gorgona.

8) En cuanto a la desnudez de Andrómeda —otra de las quaestiones disputatae en relación con nuestro mito ${ }^{22}$ - aquí no se da, ya que la doncella aparece para su tormento «vestida de blanco, con los ojos vendados», según se nos indica a través de la acotación correspondiente.

9) Un aspecto curioso es la creación del personaje de Telamón, cuya única misión parece consistir en justificar el título de la comedia. Aunque a esta función en la obra se podrían añadir otras secundarias, como la de dar celos a Perseo (si bien, realmente, esto ocurre mediante un falso Telamón bajo el que se oculta una de las hermanas de Medusa) e, incluso, la de sustituir a Fineo como estatua en el palacio real ${ }^{23}$.

10) Además, los distintos personajes secundarios (y singularmente Culebrina) van protagonizando en la obra diversas escenas que contribuyen al desarrollo de la trama, llena de enredos y engaños, de varias escenas de caza, de cánticos con recitaciones, repeticiones de estribillos y acompañamiento musical; y, también, de espectaculares cambios de escenario relacionados con sueños y hechizos que, sin duda, requirieron en su día — suponiendo que la obra llegara a representarse- un

\footnotetext{
Véase Cristóbal López (1989: 76, n. 36).

23 De hecho, el nombre de Telamón significa precisamente 'estatua' y procede directamente del griego. No obstante, entre los diversos héroes mitológicos con este nombre no hallamos ninguno que se relacione con la historia de Perseo ni con estatua alguna. El Telamón más célebre es uno de los argonautas, padre de Áyax y Teucro (héroes de la guerra de Troya). Véase Grimal (1986: 496, s. v. Telamón).
} 
gran despliegue de tramoyas escénicas (a las cuales no deja de aludir metateatralmente Culebrina).

11) Uno de los aspectos más sorprendentes de la trama es el hecho de que, gracias a sus artes adivinatorias, Medusa conoce de antemano que Perseo acabará dándole muerte. Pese a ello, la gorgona tratará de retrasar el momento inevitable a través de sus enredos y, al fin, llegará a creer que al convertir a Telamón en estatua ha logrado eludir su propio destino. De ahí que, bajando la guardia, se eche a dormir a los pies de la estatua liberando a sus hermanas de la oportuna vigilancia, lo que le acarreará fatales consecuencias.

12) Asimismo cabe destacar en nuestra obra la mezcla de elementos paganos y cristianos. En efecto, dentro del ambiente general, pretendidamente mítico, aparecen referencias a la tradición cristiana como la alusión a la festividad del Corpus (II, 169), los disparatados juramentos como «voto al rabo de Caifás» (I, 862) y «por la Mosa [sic] de Pilatos» (II, 401), pero también «por Baco puro» (I, 852) o la referencia al «camino de San Beltrán» (II, 575), expresiones todas ellas puestas en boca de Culebrina. También dentro de esta tendencia podríamos enmarcar la presencia de una reliquia a la que se atribuyen poderes como talismán, si bien no se relaciona con ningún objeto ligado a un santo cristiano, sino que se trata de

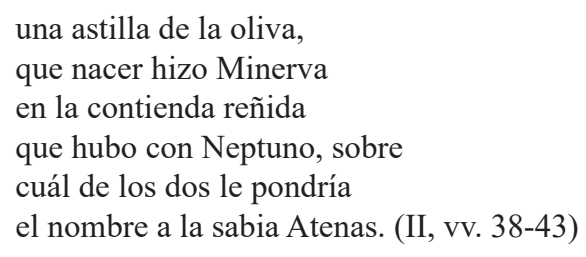

Semejante objeto mágico, otorgado por la propia Palas, sirve supuestamente de protección a Telamón, aunque al final no logrará impedir su petrificación por Medusa.

13) Por otro lado se dan también elementos procedentes de la tradición cultural europea, como la alusión al carnaval o la aparición de unos arlequines, cuya funcionalidad no parece demasiado justificada, más allá de la propia espectacularidad del efecto.

Así pues, esta pieza teatral constituye una versión libérrima del mito de Perseo en la que la fábula clásica se amolda a los propósitos del autor, que básicamente consisten en combinar lo cómico y lo espectacular para crear una obra entretenida sin mayores pretensiones que la de insertar una historia mitológica en el gusto barroco de su autor y de su posible público. Además del misterio que rodea a Ferrera y Pasqual, la obra nos deja en su cierre una nueva incógnita al prometernos una continuación: 


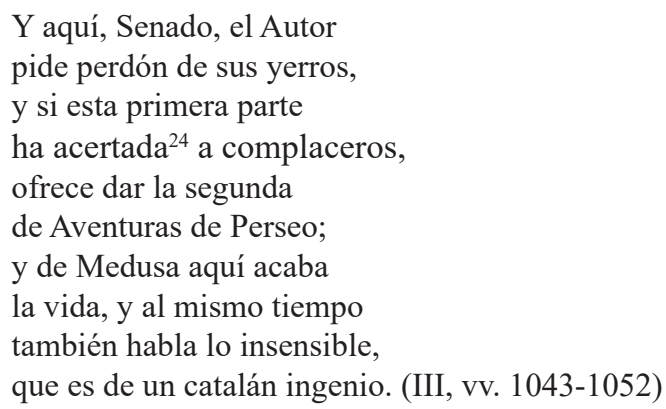

Ignoramos si el «catalán ingenio» llegó a componer la prometida segunda parte de la obra, en la que probablemente se hubiera propuesto narrar el regreso del héroe a su tierra. Tal vez con ello se habrían despejado las incógnitas sobre los orígenes de Perseo y sus amores con la misteriosa dama llamada Diana. Por lo demás, el título de Aventuras de Perseo es el tercero de los que encabezan el volumen (tras la aclaración de que se trata de una «comedia nueva»), lo que sugiere que en él se contiene una única pieza teatral; $y$, efectivamente, con los versos transcritos termina el tomo, sin dar paso a la supuesta continuación.

En definitiva, nos hallamos ante una curiosa muestra de comedia posbarroca basada en los modelos del teatro clásico español. El autor domina la técnica compositiva propia de las comedias de los grandes dramaturgos del Arte Nuevo: polimetría, presencia de varias tramas y de numerosos personajes, mezcla del elemento cómico con el serio. A ello podemos añadir la elección de un asunto mitológico, con la típica modificación de la materia mítica original, así como el calco de diversos pasajes clásicos de nuestro teatro aurisecular. Por otro lado, el influjo de la comedia de magia, típicamente dieciochesca, resulta evidente desde el propio título de la obra, alusivo a «los encantos de Medusa». Otros aspectos resultarían, desde nuestro punto de vista, más discutibles en cuanto a la adscripción propiamente tardobarroca de la pieza de Ferrera y Pasqual: así, la espectacularidad escenográfica o la tendencia métrica hacia el romance, rasgos que podemos encontrar igualmente en las comedias de Lope y — sobre todo-Calderón.

Por lo que se refiere al tratamiento de la historia, la mayor diferencia entre esta comedia y las de los dos mayores genios de la dramaturgia áurea tiene que ver con la alteración del orden lógico de los episodios, que se traduce en la concentración de las grandes hazañas del héroe (salvo la muerte de Medusa) en la primera jornada: justo al revés que Calderón, quien va dilatando el grueso de la trama en aras de la resolución final de todos los conflictos abiertos. Otras novedades de Ferrera y Pasqual se encontrarían en la presentación de Medusa como hechicera, en

24 Quizá resulte un tanto forzado ver aquí un catalanismo morfosintáctico (en este caso la concordancia del participio con el sujeto). Tal vez se trate más bien de un error tipográfico. 
el protagonismo que adquieren los personajes de las otras dos gorgonas o el del gracioso Culebrina y en la introducción del personaje de Telamón.

Es así como nuestro «catalán ingenio» logra componer una pieza entretenida y de factura impecable que sin duda resultaría del agrado del público de su época. Sin embargo, más allá de la composición dramática, el rasgo más llamativo de esta obra radica en la peculiaridad de presentarnos a una Andrómeda (y, por extensión, a unos etíopes) de piel negra; rasgo que por sí solo convertiría ya esta comedia de Ferrera en una de las adaptaciones más originales de la fábula de Perseo con las que cuenta la literatura española.

Recibido: 17/09/2015

Aceptado: 13/10/2015

\section{REFERENCIAS BIBLIOGRÁFICAS Y OBRAS CITADAS}

Alfonso X el Sabio (1957). General Estoria. Ed. de Alfonso Solalinde / Lloyd A. Kasten / Víctor R. B. Oelschläger. Madrid: CSIC, Instituto «Miguel de Cervantes».

Añorbe y Corregel, Tomás de (1738). Zarzuela nueva. Júpiter y Dánae, fiesta que se puede hacer en cualquier casa particular, asi por no tener teatro que lo embarace, como por sus pocas personas [...]. En Madrid: por Gabriel Ramírez.

Apolodoro (1985). Biblioteca. Trad. y notas de Margarita Rodríguez. Madrid: Biblioteca Clásica Gredos.

Bersuire, Pierre (ms. s. f; data del siglo Xv). Morales de Ovidio. Trad. de Alfonso de Zamora. Biblioteca Nacional, signatura MSS10144.

Bustamante, Jorge de (s. f). Las Metamorphoses, o transformaciones del excelente poeta y filósofo Ovidio, noble caballero patricio romano. Traducido del latín en romance. Amberes: Jean Steelsius, impresor.

Calderón de la Barca, Pedro (1995). Andrómeda y Perseo. Edición crítica, con introducción y notas de José María Ruano de la Haza. Kassel, Edition Reichenberger / Pamplona: Universidad de Navarra.

_ (1998). La gran comedia Fortunas de Andrómeda y Perseo. Edición electrónica publicada en HTML por Vern Williamsen, correspondiente a la de Rafael Maestre (Almagro, 1994). (2006). La vida es sueño. Madrid: Cátedra.

Colodrero de Villalobos, Miguel (1629). «Soneto 8. "No hay cuidado a quien no engañe el interés" [Júpiter (dios con voluntad rendida)]», en Varias Rimas. Córdoba: Salvador de Cea Tesa, p. 8.

Comedia famosa intitulada: Conquistar un imposible. De un ingenio catalán, sin nombre de autor ni lugar ni fecha de edición; aunque en la portadilla sí que consta la indicación: «Véndese en casa de Ignacio Guasch Impresor, en la calle de la Bocaria».

Cossío, José María de (1998). Fábulas mitológicas en España (2 vols.) Madrid: Istmo.

Cristóbal López, Vicente (1989). «Perseo y Andrómeda: versiones antiguas y modernas». Cuadernos de Filología Clásica, número 23. Madrid: UCM, pp. 51-96. 
Cristóbal López, Vicente (1997). «Andrómeda negra», en Humanismo y pervivencia del mundo clásico: homenaje al profesor Luis Gil. Coordinado por José María Maestre Maestre, Luis Charlo Brea y Joaquín Pascual Barea, pp. 325-336.

Cruz de Castro, Marichu (1993). Romances de la Antigüedad Clásica. Madrid: Ediciones Clásicas, Colección Ruta de la Memoria, pp. 28-33.

Cueva, Juan de la (1588). «Perseo liberta de la muerte a Andrómeda», en Coro febeo de romances historiales. Sevilla: Juan de León, impresor.

Fábula de Andrómeda y Perseo. A don Pedro Sarmiento de Mendoza, Gentilhombre de la Boca del Rey D. Felipe Cuarto el Grande nuestro señor, Caballero de la orden de Calatrava [sin fecha ni lugar de edición]. Ejemplar custodiado en la Biblioteca Nacional, bajo la signatura VE/157/3.

Júpiter y Dánae. Zarzuela en 3 jornadas; y baile. Música de D. Antonio Literes. Manuscrito en la Biblioteca Nacional (signatura M/1579). Fechado hacia 1700.

Ferrera y Pasqual, Ignacio (1743). Comedia nueva- También habla lo insensible, Los encantos de Medusa y Aventuras de Perseo. Barcelona: Por Joseph Giralt, impresor.

Grimal, Pierre (1986). Diccionario de mitología griega y romana. Trad. de Francisco Payarols. Barcelona: Paidós.

López Durán, Agustín (1945). Romancero general o colección de romances castellanos anteriores al siglo XVIII, recogidos, ordenados, clasificados y anotados por Don Agustín López Durán (2 vols.). Madrid: Ediciones Atlas / Biblioteca de Autores Españoles. Desde la formación del lenguaje hasta nuestros días. Tomo I, número 457, Juan de la Cueva: «Perseo libera de la muerte a Andrómeda», pp. 302-304.

Mendoza Díaz-Maroto, Francisco (1999). «Manuscritos e impresos de 1701 a 1750 en una biblioteca de Albacete». Al-Basit. Revista de Estudios Albacetenses. № 42, pp. 103-155.

Mey, Felipe (1586). Del Metamorfoseos de Ovidio en Otava Rima. Traduzido por Felipe Mey. Siete libros. Con otras cosas del mismo. En Tarragona: por Felipe Mey.

Ovidio Nasón, Publio (2002). Las metamorfosis. Texto revisado y traducido por Antonio Ruiz de Elvira (edición bilingüe latín-español). 2 vols. Madrid: CSIC. Alma Mater.

Palacios Fernández, Emilio (2003). «El teatro tardobarroco y los nuevos géneros dieciochescos». En Javier Huerta Calvo (dir.), Historia del teatro español (2 vols.). Vol. II, Del siglo xviii a la época actual. Madrid: Gredos, 2003, pp. 1553-1576.

Pérez de Moya, Juan (1977). Filosofia secreta (2 vols.). Barcelona: Glosa/Col. La Cara Oculta.

Pérez Sigler, Antonio (1609). Metamorfoseos del excelente poeta Ovidio Nasson. Traducidos en verso suelto y octava rima: con sus alegorías al fin de cada libro. Por el doctor Antonio Pérez Sigler natural de Salamanca. Nuevamente agora [...] añadido por el mismo autor un diccionario poético copiosísimo. Burgos: por Juan Baptista Varesio.

Sánchez de Viana, Pedro (1589). Las Transformaciones de Ovidio: Traducidas del verso latino, en tercetos, y octavas rimas, por el Licenciado Viana, en lengua vulgar castellana. Con el comento, y explicaciones de las fábulas: reduciéndolas a Filosofia natural y moral, y Astrología e Historia. Valladolid: por Diego Fernández de Córdoba.

Timoneda, Juan de (1573): Rosas de romances. Valencia: Juan Navarro.

Tostado, Alonso [de Madrigal] (1677/1679): Sobre Eusebio, mineral de letras divinas y humanas, en la historia general de todos los tiempos, y Reinos del mundo, según los 
comentarios del ilustrísimo y venerable doctor, luz de la Iglesia, y de la Cristiandad, Don Alonso Tostado, obispo que fue de Ávila. Madrid: oficina de Melchor Sánchez (vol. I); Madrid: Francisco Sanz (vol. II).

Vega CARPIO, Félix Lope de (1638). «Atada a un risco, Andrómeda lloraba», en Los palacios de Galiana (obra incluida en la Parte veinte y tres de las comedias de Lope Félix de Vega y Carpio) Madrid: María de Quiñones.

(1983). «De Andrómeda», en Obras poéticas. Rimas. Rimas sacras. La Filomena. La Circe. Rimas humanas y divinas del licenciado Tomé de Burguillos. Edición, introducción y notas de José Manuel Blecua. Barcelona: Planeta.

(1984). La Andrómeda (poema inserto en la obra La Filomena), en Poesía selecta. Edición de Antonio Carreño. Madrid: Cátedra, pp. 726-748.

(1985). La fábula de Perseo o la bella Andrómeda. Edición crítica, introducción y notas de Michael D. Mc. Gaha: Kassel Edition Reichenberger.

Vitoria, Baltasar de (1620/1623): Teatro de los dioses de la gentilidad. Primera parte, Salamanca: en casa de Diego Ramírez; segunda parte, Salamanca: en casa de Diego de Cussio.

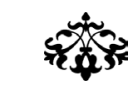

Perseo en la comedia tardobarroca: Ignacio Ferrera y Pasqual

Resumen: Entre los géneros que recrearon el mito de Perseo en la literatura española sobresale la comedia barroca. Lope y Calderón compusieron dos conocidas obras sobre este asunto mitológico, que llegaría a su máxima expresión dramática con el auto sacramental Perseo y Andrómeda del propio Calderón. Sin embargo, ya casi mediado el siglo xviii, es decir, en el tardobarroco, encontramos una curiosa obra debida a un cierto Ignacio Ferrera y Pasqual, que constituye una de las versiones más sui generis de la historia de Perseo. Presentamos en este artículo un análisis de esta sorprendente pieza.

Palabras clave: Perseo; literatura española; comedia; barroco tardío; Ignacio Ferrera y Pasqual.

Perseus in the late baroque comedy: Ignacio Ferrera y Pasqual

ABSTRACT: Among the genres that recreated the myth of Perseus in Spanish literature the Baroque comedy stands out. Lope and Calderón composed two well-known works about this mythological subject, which would reach its maximum dramatic expression with the Calderon's auto sacramental Perseus and Andromeda. However, almost in the middle of the 18 th century, i.e. in the late baroque, we found a curious work due to a certain Ignacio Ferrera y Pasqual, which constitutes one of the more sui generis versions of the story of Perseus. We present in this paper an analysis of this amazing piece.

KeY words: Perseus; Spanish literature; Comedy; late Baroque; Ignacio Ferrera y Pasqual. 
TERESA DE JESÚS (1515-1582)

Guillermo Serés (Universidad Autónoma de Barcelona)

La imaginación de Santa Teresa: virtudes y desatinos de «la loca de la casa»....... 11

Ana Garriga EsPino (Universidad Autónoma de Madrid)

El desafío editorial de las cartas de Teresa de Jesús.

LeCTURAS REPUBLICANAS DEL QUIJOTE

RAQUEL ArIas (Universidad Autónoma de Madrid)

León Felipe alista a don Quijote en el bando republicano. 57

MANUEl LóPez ForJas (Universidad Autónoma de Madrid)

El Quijote y la realidad viva de las Españas: la visión histórica

de Pedro Bosch-Gimpera.

CArmen Madorrán Ayerra (Universidad Autónoma de Madrid)

El Quijote como utopía necesaria: la mirada de Adolfo Sánchez Vázquez 85

\section{OTROS TEMAS}

SònIA BoADAS (Universitat Autònoma de Barcelona)

Libros y librerías: la recepción de Commynes en España 101

Lucila Lobato Osorio (Universidad Nacional Autónoma de México)

La noticia de la muerte de Policisne de Boecia: expresiones de dolor en un libro inconcluso.

María Gutiérrez Padilla (Universidad Nacional Autónoma de México)

La escenografía en el teatro caballeresco 131

ADRIÁn FERnÁNDEZ (Université de Fribourg)

Dos entremeses «auditivos» y sus niveles: hacia un metateatro visual. 145

David González de la Higuera Garrido (Universidad Complutense de Madrid) La visión premonitoria de Alonso en El caballero de Olmedo:

otra recuperación de lo popular

Esther Fernández LóPEz (UNED)

Perseo en la comedia tardobarroca: Ignacio Ferrera y Pasqual 169

Manuel Piqueras Flores (Universidad Autónoma de Madrid)

De La hija de Celestina $a$ La ingeniosa Elena: estructura narrativa, género literario e interpolación 
Dagoberto CÁceres Agullar (Western University Canada)

Realismo incesante: desde Celestina hacia su recepción 201

TeXTOS INÉDITOS

Davinia Rodríguez Ortega (Universidad Pública de Navarra)

Auto sacramental del Juego del Hombre, de Luis Mejía de la Cerda:

edición crítica 


\section{EDAD DE ORO}

Revista de Filología Hispánica XXXIV

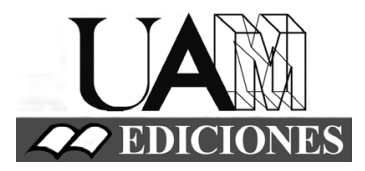




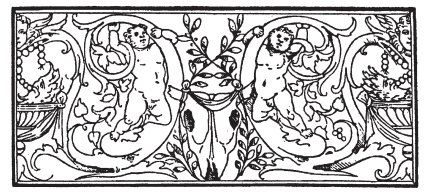

\section{Edad de Oro. Revista de Filología Hispánica}

ISSN: 0212-0429

Dirección:

Teodosio Fernández

Secretaría y edición:

José Ramón Trujillo

Comité científico internacional:

Carlos Alvar (Univ. de Ginebra)

Ignacio Arellano (Univ. de Navarra)

Javier Blasco (Univ. de Valladolid)

Alberto Blecua (UAB)

Jean Canavaggio (Univ. de París X)

Laura Dolfi (Univ. de Turín)

Aurora Egido (Univ. de Zaragoza)

Víctor García de la Concha (RAE)

Luciano García Lorenzo (CSIC)

Joaquín González Cuenca (Univ. de Castilla-

La Mancha)

Agustín de La Granja (Univ. de Granada)

Begoña López Bueno (Univ. de Sevilla)

Michel Moner (Univ. de Toulouse III)

Joan Oleza (Univ. de Valencia)

Alfonso Rey (Univ. de Santiago)

Lina Rodríguez Cacho (Univ. de Salamanca)

Leonardo Romero Tobar (Univ. de Zaragoza)

Aldo Ruffinatto (Univ. de Turín)

Lía Schwartz (City University of New York)
Redacción y admisión de originales:

Teodosio Fernández

Edad de Oro

Departamento de Filología Española

Universidad Autónoma de Madrid

28049 Madrid (España)

Tfno.: +0034914974090

correo: teodosio.fernandez@uam.es

Distribución, suscripción y venta:

Servicio de Publicaciones de la UAM

Universidad Autónoma de Madrid

28049 Madrid (España)

Intercambio de publicaciones:

Biblioteca de la Facultad de Filosofía y

Letras (UAM)

Universidad Autónoma de Madrid

28049 Madrid (España)

Han colaborado en este volumen:

Departamento de Filología Española (UAM)

Facultad de Filosofia y Letras (UAM)

Edad de Oro se recoge, entre otras, en las siguientes bases de datos: SCOPUS, MLA Database, HLAS, Latindex, PIO-Periodical Content Index, ISOC, Dialnet, MIAR, ERIH, DICE, Sumaris CBUC, Ulrich's. Se encuentra evaluada en CIRC: A; INRECH: primer cuartil, posición 6 de 50; MIAR difusión ICDS live: 9.977; SCImago Journal \& Country Rank: H Index 2, SJR 0,101, Q4; RESH índice de impacto: 0.041; ERIH: A INT1; Carhus Plus+2014: C. 